\title{
CYTOKINES PROFILE AND CLINICAL-METABOLIC ALTERATIONS IN HIV-1- INFECTED INDIVIDUALS WITH AND WITHOUT LYPODISTROPHY
}

\author{
THESIS. L. C. R. Pontes Cardoso submitted this thesis for her Doctorate in Tropical \\ Diseases at Botucatu School of Medicine, São Paulo State University, UNESP, \\ Botucatu, São Paulo, Brazil, 2005.
}

\section{Advisor: Professor Paulo Câmara Marques Pereira}

\begin{abstract}
Highly active antiretroviral therapy (HAART) has lead to a dramatic decrease in the morbidity of patients infected with HIV. However, metabolic side effects, including lipodystrophy and dyslipidemia, have been reported in patients treated with antiretroviral therapy (HAART). The aim of this study was to analyze the clinical and metabolic alterations and the cytokines TNF- $\alpha$, IFN- $\gamma$, IL-2, IL-10 and TNF-II receptors profile in the serum of treated HIV-1-infected individuals with or without lipodystrophy. Eighty-four adult patients were analyzed, 42 females and 42 males, their mean age was 37 years old, and they received HAART for at least 15 months. These patients were ambulatory outpatients from the Infectious and Parasitary Disease Area of Botucatu School of Medicine, UNESP. Subsequently the individuals were distributed into 2 groups, G1: 42 HIV-infected individuals with lipodystrophy, and G2: 42 HIV-infected individuals without lipodystrophy. Among the antiretrovirals used, stavudine was more associated to the lipodystrophy group and zidovudine to the group without lipodystrophy. CD4, CD8, viral load, glucose, albumin, and the circulating lipid did not present any difference in the group comparison, except for triglyceride that was elevated in the lipodystrophy group and HDL which was present in low concentration in more patients of $\mathrm{G} 1$. The cytokines TNF- $\alpha$, TNF-RII, and IL-10 profile presented high levels in the lipodystrophy group; also it was positively correlated with this group. On the other hand, IL-2 and IFN- $\gamma$ presented low levels in this group. High levels of TNF- $\alpha$ and its receptor seem to be associated to the development of lipodystrophy in patients receiving HAART.
\end{abstract}

KEY WORDS: dyslipidemia, cytokines, HIV, lipodystrophy

\section{CORRESPONDENCE TO:}

LIZANDRA CARLA RIGOLETTI PONTES CARDOSO, Departamento de Doenças Tropicais e Diagnóstico por Imagem da Faculdade de Medicina de Botucatu, UNESP, Distrito de Rubião Jr, s/n, 18618-000, Botucatu, SP, Brasil. Email: ppereira@fmb.unesp.br 